\title{
Heme and innate immunity: new insights for an old molecule
}

\author{
Maria Augusta Arruda/+ , Aurélio V Graça-Souza*, Christina Barja-Fidalgo
}

\author{
Departamento de Farmacologia, Instituto de Biologia Roberto Alcântara Gomes, Universidade do Estado do Rio de Janeiro, Av. 28 \\ de setembro 87, 20551-030 Rio de Janeiro, RJ, Brasil *Instituto de Bioquímica Médica, Universidade Federal do Rio de Janeiro, \\ Rio do Janeiro, RJ, Brasil
}

Hemolytic episodes such as sickle cell disease, malaria and ischemia-reperfusion occurrence are often associated to the statement of an inflammatory response which may develop or not to a chronic inflammatory status. Although these pathological states are triggered by distinct etiological agents, all of them are associated to high levels of free heme in circulation. In this review, we aim to focus the very recent achievements that have led to the statement of free heme as a proinflammatory molecule, which may play a central role during the onset and/or persistance of inflammation during these pathologies.

Key words: inflammation - heme - hemolytic episodes

Heme is a ubiquitous molecule crucial for the life as we know it, once it is the prosthetic moiety of a great number of proteins which take part on a variety of vital processes. Heme biosynthesis is a very controlled process that occurs on every nucleated cell types, involving both mitochondrial and cytoplasmatic enzymatic pathways (Shemin 1989). The major part of all heme in a cell is generally associated to proteins that require heme in order to be active or functional, but it is reasonable to assume the existence of a modest amount of free heme, which may have both precursor and regulatory functions (Ponka 1999).

Once free heme is released to both intra- and extracellular milieu, it may work as a double-edge sword, displaying both protective and deleterious actions. Among the protective effects, free heme can influence the expression of several genes per se, including enzymes involved on its own synthesis (Sassa 1976, Yamamoto et al. 1982). Through this ability, free heme regulates the proliferation and differentiation of several cell types (Ishii \& Maniatis 1971, Granick \& Sassa 1978, Abraham 1991). In contrast, high amounts of free heme can be extremily deleterious to the organism, catalyzing non-enzymatic generation of reactive oxygen species (ROS), leading to oxidative stress that can cause cell damage and tissue injury (Vercellotti et al. 1994). It can also intercalate in membrane and alter the dynamic of cellular structures (Balla et al. 1991, Beri \& Chandra 1993, Ryter \& Tyrrel 2000).

Financial support: CNPq, Faperj and SR-2/Uerj.

The present paper was presented at the International Symposium on Nitric Oxide, Cytokines and Inflammation, in June 2004, Rio de Janeiro, Brazil.

+Corresponding author. Fax: +55-21-2587-6808. E-mail: augusta@uerj.br.

Received 17 December 2004

Accepted 28 March 2005
Such diverse effects require prompt action of the organism against an undesirable rise on free heme levels. On circulation, the main scavenging system is leaded by hemopexin, which binds to free heme and delivers it to liver, where it is degraded by the enzyme heme oxygenase (HO). However, the scavenging of free heme by hemopexin in cases of moderate to intense hemolysis collapses, corroborating to the accumulation of free heme in circulation (Muller-Eberhard \& Fraig 1993).

$\mathrm{HO}$ are ubiquitous enzymes able to catalyze the initial and rate-limiting step in the oxidative degradation of heme to bilirubin, producing equimolar amounts of biliverdin, free iron $(\mathrm{Fe})$ and carbon monoxide $(\mathrm{CO})$ (Choi \& Alam 1996). There are three known HO isoforms: the constitutive isoforms HO-2 and HO-3 and the inducible isoform HO-1. Under normal conditions, most cell types express very low or undetectable levels of HO-1 and constituve levels of HO-2. However, a number of stimuli can trigger HO-1 gene expression through a plethora of signaling pathways, including proinflammatory agents (Maines 1997, Immenschuh \& Ramadori 2000).

\section{Hemolytic episodes and inflammation}

The correlation between acute and chronic inflammation and hemolytic episodes has been extensively reported in the literature (Wun 2001), but defining the etiological agent(s) that promote such inflammatory states remained obscure, probably due to the complexity of each of these pathological states. Recently, our group and others have been investigating the effect of free heme in triggering acute and/or chronic inflammation during hemolytic episodes.

Heme and onset of inflammation: neutrophil activation - Until late 1980s, the association of free heme found in circulation during hemolytic episodes and inflammation used to be restrained to the deleterious action of this molecule generating ROS production via Fenton reaction, and its ability to promote peroxidation and oxidation of biomolecules. Recent studies have shown that free heme, on concentrations found during hemolytic episodes, induces the expression of proinflammatory 
adhesion molecules both on endothelium and blood cells in vitro and in vivo, as well as increase on vascular permeability and leukocyte influx (Wagener 1997, Wagener 2001). Graça-Souza et al. (1999) reported that heme was able to directly activate protein kinase C (PKC) in the insect Rhodnius prolixus. PKCs are a family of kinases highly conserved throughout evolution that play proeminent roles on the inflammatory response.

Of all cells that constitute the "innate imunity army", neutrophils are the first line of host defense against invading microorganism, being promptly recruited to inflamed loci in response to infection or tissue injury. Once activated, neutrophils are able to phagocytose, to release granular lytic enzymes and antimicrobial polypeptides into the phagolysosome, and to generate large amounts of ROS as well as reactive nitrogen species (Edwards 2000). These prerogatives set neutrophil as a suitable cell type in order to investigate leukocyte responsiveness to free heme. On this study we reported that free heme acts as a prototypical proinflammatory molecule, able to induce neutrophil migration both in vivo and in vitro per se (GraçaSouza et al. 2002). Interaction of free heme with human neutrophils leads to actin cytoskeleton reorganization and NADPH oxidase-dependent ROS generation through the induction of protein kinase $\mathrm{C}$ (PKC) activity. It also increases interleukin (IL)-8 expression in a PKCindependent manner, providing the first clue of the pleithropic mechanisms of action of free heme on human neutrophils. This work was then the first evidence that heme is able to trigger an inflammatory response itself activating leukocyte responsiveness (Graça-Souza et al. 2002).

Heme and commitment to chronic inflammation: inhibition of neutrophil apoptosis - Neutrophil apoptosis and subsequent clearance by phagocytes are critical to the resolution of acute inflammation (Savill 1997, Ward et al. 1999a). Under normal conditions, these terminally differentiated cells have a very short half-life, being committed to programmed cell death (apoptosis). During this process, cell membrane integrity is maintained, avoiding the release of pro-inflammatory and potentially cytotoxic agents and the subsequent amplification of the inflammatory response. Apoptotic neutrophils also express surface markers that allow their recognition and non-phlogistic ingestion by professional phagocytes such as macrophages, or potential phagocytes such as fibroblasts and mesangial cells (Savill et al. 2002).

Agents that promote neutrophil responsiveness such as interleukin IL-8, granulocyte macrophage colony stimulating factor (GM-CSF), lipopolysaccharide (LPS) and leukotriene $\mathrm{B}_{4}$ delay human neutrophil apoptosis (Colotta et al. 1992, Lee at al. 1993, Herbert te al. 1996, Kettritz et al. 1998). These stimuli promote neutrophil survival by modulating intracellular signaling pathways, including the mitogen activated protein (MAP) kinases, especially the extracellular-regulated kinase (ERK) and phosphoinositol 3-kinase (PI3K)/Akt pathways (Klein et al. 2000, 2001). Evidence has shown that activation of NF-kB pathway activation has a protective effect in several cell types, regulating the expression of anti-apoptotic genes (Ward et al. 1999b).
We then demonstrated that free heme is also involved on the delay of neutrophil apoptosis, activating prosurvival pathways shared by classical anti-apoptotic agents. This phenomenon is totally dependent on ROS generation, which seems to up-regulate multiple signaling pathways (PI3K/AKT, ERK and NF-kðB) required for heme anti-apoptotic effect. Moreover, the inhibition of HO activity partially reverted heme delay of neutrophil apoptosis, but this effect does not depend on biliverdin or bilirubin production, once these $\mathrm{HO}$ by-products were not able to mimic heme effects. It suggests that $\mathrm{CO}$ and $\mathrm{Fe}$ might be the HO catabolytes involved on this phenomenon.

Heme also promotes differential expression of pro- and anti- apoptotic Bcl-2 members. Bcl-2 family constitutes an evolutionary conserved group of anti- and pro-apoptotic proteins. The anti-apoptotic members (e.g. Bcl-2, Bcl- $\mathrm{X}_{\mathrm{L}}$, Mcl-1, A1) act promoting stability of mitochondrial outer membrane and/or impairing the oligomerization and consequent insertion of pro-apoptotic Bax-like proteins into the mitochondria and consequent release of proapoptotic proteins contained on the mitochondrial intermembrane space (Newmeyer \& Ferguson-Miller 2003). A second group of pro-apoptotic Bcl-2 members (e.g. Bad, Bid) comprises proteins that modulate negatively the antiapoptotic Bcl-2 proteins and positively the pro-apoptotic ones (Droin \& Green 2004).

In most cell types, the expression and activity of protective $\mathrm{Bcl}-2$ members is higher than pro-apoptotic ones. However, mature neutrophils display the opposite, what is quite reasonable once these cells are committed to programmed cell death. Neutrophils constitutively express pro-apoptotic proteins, while the expression of anti-apoptotic Bcl-2 members is very low or undetectable in resting cells. These anti-apoptotic proteins are highly and transiently expressed when neutrophils are exposed to survival factors, like IL-8 and GM-CSF (Akgul 2001, Maianski et al. 2003).

$\mathrm{Bcl}-\mathrm{X}_{\mathrm{L}}$ synthesis and Bad degradation were also observed on heme-treated cells (Arruda et al. 2004). Unpublished observations of our laboratory show that heme preserves mitochondria stability and shifts the Bcl$\mathrm{X}_{\mathrm{L}} /$ Bad ratio in a ROS-dependent manner, requiring the same signaling pathways that regulate heme anti-apoptotic effect.

These findings attest to a major role of free heme in the onset of inflammation associated with hemolytic diseases as well as the statement of chronic inflammation associated to such disorders: it activates neutrophil functions, and delay neutrophil apoptosis, probably maintaining mitochondria stability. A scheme of the putative mechanism of action of free heme on neutrophils is presented on the Figure.

Comparing experimental data and clinical evidences: sickle cell disease - Acute and chronic inflammations are important features of hemolytic events, particularly on sickle cell disease, a hereditary disorder caused by a single point mutation in one of the genes encoding hemoglobin (Bunn 1997). On this disease, spontaneous and non-septic hemolysis is a hallmark, 
being an excellent model to analyze the putative impact of free heme on the inflammatory response. It has been shown that increased levels of heme in plasma are accompanied by a rise on cytokine and chemokine concentrations, as well as enhanced leukocyte function on sickle cell disease patients (Davenport et al. 1996, Mollapour et al. 1998, Gonçalves et al. 2001), events associated with an intense inflammatory response. Of note, this inflammatory status usually develops into chronic inflammation (Kaul \& Hebbel 2000, Wun 2001). These events may lead to vaso-occlusion, which causes pain crisis and organ failure, two serious symptoms correlated to this disorder, as well as support the experimental achievements correlating heme and inflammation.

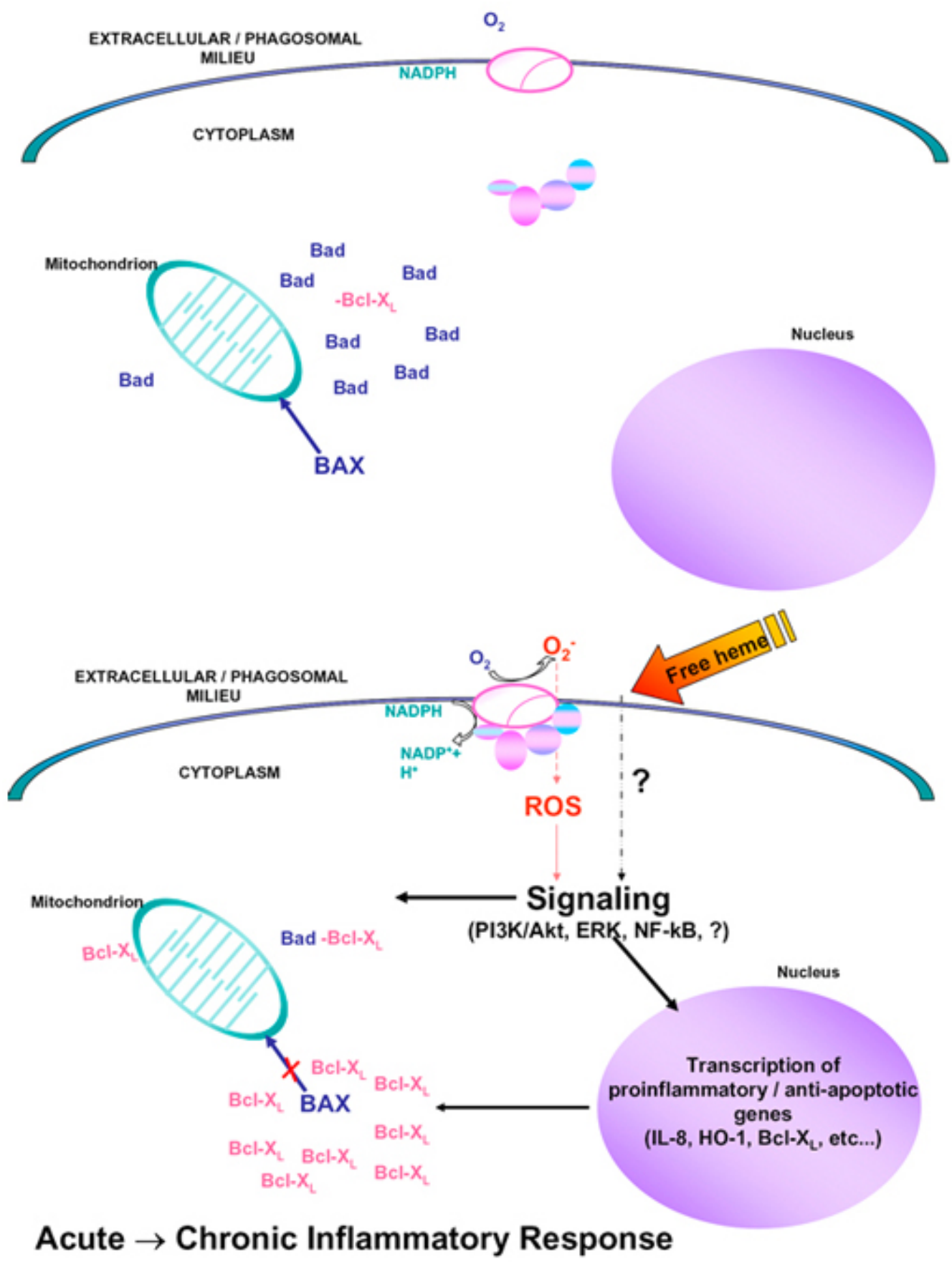

Putative mechanism of action of free heme on neutrophils. Resting mature neutrophils express high levels of pro-apoptotic Bcl-2 protein $\mathrm{Bad}$ while very low or undetectable amounts of the anti-apoptotic protein Bcl- $\mathrm{X}_{\mathrm{L}}$, facilitating Bax insertion into the mitochondria and consequent launch of the apoptotic cascade. When neutrophil interact with free heme, the activation of multiple signaling pathways occurs, which can be triggered or not by NADPH oxidase-dependent reactive oxygen species (ROS) production. This activation ultimately results in degradation of Bad and de novo synthesis of Bcl- $\mathrm{X}_{\mathrm{L}}$, corroborating for the maintenance of mitochondria stability, as well as upregulates the expression of proinflammatory and anti-apoptotic genes. 


\section{Concluding remarks}

The recent advance on the study of heme as a proinflammatory molecule brings up hope for the development of new strategies to ameliorate acute and

\section{REFERENCES}

Abraham NG 1991. Molecular regulation - biological role of heme in hematopoiesis. Blood Rev 5: 19-28.

Akgul C, Moulding DA, Edwards SW 2001. Molecular control of neutrophil apoptosis. FEBS Lett 487: 318-322.

Arruda MA, Rossi AG, de Freitas MS, Barja-Fidalgo C, GracaSouza AV 2004. Heme inhibits human neutrophil apoptosis: involvement of phosphoinositide 3-kinase, MAPK, and NFkappaB. J Immunol 173: 2023-2030.

Balla J, Jacob HS, Eaton JW, Belcher JD, Vercellotti GM 1991. Hemin: a possible physiological mediator of low density lipoprotein oxidation and endothelial injury. Arterioscler Thromb 11: 1700-1711.

Beri R, Chandra R 1993. Chemistry and biology of heme. Effect of metal salts, organometals and metalloporphyrins on heme synthesis and catabolism, with special reference to clinical implications and interactions with cytochrome P-450. Drug Metab Rev 25: 49-152.

Bunn HF 1997. Pathogenesis and treatment of sickle cell disease. $N$ Engl J Med 337: 762-769.

Choi AM, Alam J 1996. Heme oxygenase-1: function, regulation, and implication of a novel stress-inducible protein in oxidant-induced lung injury. Am J Respir Cell Mol Biol 15: 9-19.

Colotta F, Re F, Polentarutti N, Sozzani S, Mantovani A 1992. Modulation of granulocyte survival and programmed cell death by cytokines and bacterial products. Blood 80: 20122020 .

Davenport RD, Strieter RM, Standiford TJ, Kunkel SL 1990. Interleukin- 8 production in red blood cell incompatibility. Blood 76: 2439-2442.

Droin NM, Green DR 2004. Role of Bcl-2 family members in immunity and disease. Biochim Biophys Acta 1644: 179188.

Edwards SW 2000. Biochemistry and Physiology of the Neutrophil. Cambridge University Press, New York.

Gonçalves MS, Queiroz IL, Cardoso SA, Zanetti A, Strapazoni AC, Adorno E, Albuquerque A, Sant'Ana A., dos Reis MG, Barral A, Barral Netto M 2001. Interleukin 8 as a vasoocclusive marker in Brazilian patients with sickle cell disease. Braz J Med Biol Res 34: 1309-1313.

Graça-Souza AV, Silva-Neto MA, Oliveira PL 1999. Urate synthesis in the blood-sucking insect rhodnius prolixus. Stimulation by hemin is mediated by protein kinase C. $J$ Biol Chem 274: 9673-9676.

Graça-Souza AV, Arruda MA, de Freitas MS, Barja-Fidalgo C,Oliveira PL 2002. Neutrophil activation by heme: implications for inflammatory processes. Blood 99: 41604165.

Granick JL, Sassa S 1978. Hemin control of heme biosynthesis chronic inflammation related to hemolytic episodes. However more studies need to be performed in order to elucidate how heme interacts with the cell membrane and modulate the activity of other cells of the immune system.

in mouse Friend virus-transformed erythroleukemia cells in culture. J Biol Chem 253: 5402-5406.

Hebert MJ, Takano T, Holthofer H, Brady HR 1996. Sequential morphologic events during apoptosis of human neutrophils. Modulation by lipoxygenase-derived eicosanoids. $J$ Immunol 157: 3105-3115.

Immenschuh S, Ramadori G 2000. Gene regulation of heme oxygenase- 1 as a therapeutic target. Biochem Pharmacol 60: $1121-1128$.

Ishii DN, Maniatis GM 1978. Haemin promotes rapid neurit outgrowth in cultured mouse neuroblastoma cells. Nature 274: $372-374$.

Kaul DK, Hebbel RP 2000. Hypoxia/reoxygenation causes inflammatory response in transgenic sickle mice but not in normal mice. J Clin Invest 106: 411-420.

Kettritz R, Gaido ML, Haller H, Luft FC, Jennette CJ, Falk RJ 1998. Interleukin-8 delays spontaneous and tumor necrosis factor-alpha-mediated apoptosis of human neutrophils. Kidney Int 53: 84-91.

Klein JB, Buridi A, Coxon PY, Rane MJ, Manning T, Kettritz R, McLeish KR 2001. Role of extracellular signal-regulated kinase and phosphatidylinositol-3 kinase in chemoattractant and LPS delay of constitutive neutrophil apoptosis. Cell Signal 13: 335-343.

Klein JB, Rane MJ, Scherzer JA, Coxon PY, Kettritz R, Mathiesen JM, Buridi A, McLeish KR 2000. Granulocytemacrophage colony-stimulating factor delays neutrophil constitutive apoptosis through phosphoinositide 3-kinase and extracellular signal-regulated kinase pathways. $J$ Immunol 164: 4286-4291.

Lee A, Whyte MK, Haslett C 1993. Inhibition of apoptosis and prolongation of neutrophil functional longevity by inflammatory mediators. J Leukoc Biol 54: 283-288.

Maines MD 1997. The heme oxygenase system: a regulator of second messenger gases. Annu Rev Pharmacol Toxicol 37: 517-554.

Maianski NA, Geissler J, Srinivasula SM, Alnemri, ES, Roos D, Kuijpers TW 2004. Functional characterization of mitochondria in neutrophils: a role restricted to apoptosis. Cell Death Differ 11: 143-153.

Mollapour E, Porter JB, Kaczmarski R, Linch DC, Roberts PJ 1998. Raised neutrophil phospholipase A2 activity and defective priming of NADPH oxidase and phospholipase A2 in sickle cell disease. Blood 91: 3423-3429.

Muller-Eberhard U, Fraig M 1993. Bioactivity of heme and its containment. Am J Hematol 42: 59-62.

Newmeyer DD, Ferguson-Miller S 2003. Mitochondria: releasing power for life and unleashing the machineries of death. Cell 112: 481-490.

Ponka P 1999. Cell biology of heme. Am J Med Sci 318: 241256. 
Ryter SW, Tyrrel RM 2000. The heme synthesis and degradation pathways: role in oxidant sensitivity. Heme oxygenase has both pro- and antioxidant properties. Free Radic Biol Med 28: 289-309.

Sassa S 1976. Sequential induction of heme pathway enzymes during erythroid differentiation of mouse Friend leukemia virus-infected cells. J Exp Med 143: 305-315.

Savill J 1997. Apoptosis in resolution of inflammation. J Leukoc Biol 61: 375-380.

Savill J, Dransfield I, Gregory C, Haslett C 2002. A blast from the past: clearance of apoptotic cells regulates immune responses. Nat Rev Immunol 2: 965-975.

Shemin D 1989. An illustration of the use of isotopes: the biosynthesis of porphyrins. Bioessays 10: 30-35.

Vercellotti GM, Balla G, Balla JM, Nath K, Eaton JW, Jacob HS 1994. Heme and the vasculature: an oxidative harzard that induces antioxidant defense of the endothelium. Artif Cells Blood Substit Immobil Biotechnol 22: 207-213.
Ward C, Dransfield I, Chilvers ER, Haslett C, Rossi AG 1999. Pharmacological manipulation of granulocyte apoptosis: potential therapeutic targets. Trends Pharmacol Sci 20: 503509.

Ward C, Chilvers ER, Lawson MF, Pryde JG, Fujihara S, Farrow SN, Haslett C, Rossi AG 1999. NF-kappaB activation is a critical regulator of human granulocyte apoptosis in vitro. $J$ BiolChem 274: 4309-4318.

Wagener FA, Feldman E, de Witte T \& Abraham NG 1997. Heme induces the expression of adhesion molecules ICAM1, VCAM-1, and E selectin in vascular endothelial cells. Proc. Soc. Exp. Med. 216:456-463.

Wagener FA, Eggert A, Boerman OC, Oyen WJ, Verhofstad A, Abraham NG, Adema G, van Kooyk Y, de Witte T, Figdor CG 2001. Heme is a potent inducer of inflammation in mice and is counteracted by heme oxygenase. Blood 98:18021811. 